\title{
Advanced glycation end products upregulate angiopoietin-like protein 4 expression by activating the renin-angiotensin system in endothelial cells
}

\author{
ZHENDA ZHENG ${ }^{1}$, CAILIAN CHENG ${ }^{2}$, RUIMIN DONG ${ }^{1}$, MEI LI ${ }^{2}$, \\ ZHAOJUN XIONG ${ }^{1}$, XIAOXIAN QIAN ${ }^{1}$ and LIN CHEN $^{1}$ \\ Departments of ${ }^{1}$ Cardiovascular and ${ }^{2}$ Nephrology, The Third Affiliated Hospital of \\ Sun Yat-Sen University, Guangzhou, Guangdong 510630, P.R. China
}

Received March 6, 2015; Accepted May 5, 2015

DOI: 10.3892/br.2015.468

\begin{abstract}
The aim of the present study was to investigate the effects of advanced glycation end products (AGEs) on the expression of angiopoietin-like protein 4 (ANGPTL4) and the mechanisms of the effects in endothelial cells. Endothelial cells were incubated with various concentrations of AGEs for $24 \mathrm{~h}$ and the expression of ANGPTL4 was detected by quantitative polymerase chain reaction and western blot analysis. The concentration of angiotensin II (Ang II) in conditioned media and cell lysates was measured by enzyme-linked immunosorbent assays. Fluorescein isothiocyanate-labeled dextran filtration assays and transendothelial electrical resistance were performed to evaluate endothelial permeability. AGEs $(80 \mu \mathrm{g} / \mathrm{ml})$ increased the expression of ANGPTL4 and the levels of Ang II $(\mathrm{P}<0.05)$. Incubation with AGEs also resulted in a significant increase in endothelial permeability $(\mathrm{P}<0.05)$. However, pretreatment with the Ang II receptor blocker losartan $\left(10^{-5} \mathrm{M}\right)$ reduced the effects of AGEs $(\mathrm{P}<0.05)$. AGEs upregulated the expression of ANGPTL4 by activating a local renin-angiotensin system in endothelial cells. This may be a new mechanism by which AGEs increase endothelial permeability.
\end{abstract}

\section{Introduction}

Diabetes is a powerful and independent risk factor for coronary artery disease, stroke and peripheral arterial disease. Current evidence indicates that the increase of advanced glycation end products (AGEs) is associated with the severity of diabetic complications (1). Coronary atherosclerotic heart disease (CAD) is a leading cause of mortality worldwide. Increased endothelial permeability is the main cause of atherosclerosis.

Correspondence to: Dr Cailian Cheng, Department of Nephrology, The Third Affiliated Hospital of Sun Yat-Sen University, 600 Tianhe Road, Guangzhou, Guangdong 510630, P.R. China

E-mail: chengcailian3@163.com

Key words: advanced glycation end products, endothelial cells, renin-angiotensin system, angiopoietin-like protein 4
Accumulating evidence suggests that atherosclerosis is a complex process influenced by multiple procedures and mediators (1). AGEs may induce oxidative stress generation and inflammatory reactions in various cell types, as part of their involvement in the vascular complications of diabetes. The effects of AGEs on vessel wall homeostasis may account for the rapid progression of atherosclerosis associated with diabetes.

Angiopoietin-like protein 4 (ANGPTL4) is a member of the angiopoietin family that is a secretory glycoprotein highly expressed in adipose tissue, liver, placental tissue and ischemic tissue (2). Previous studies suggest that ANGPTL4 has complex and contradictory roles in vascular biology and tumor metastasis (3-5). However, the effects of AGEs on ANGPTL4 in endothelial cells remain uncertain and not fully understood.

The purpose of the present study was to characterize the effects of AGEs on ANGPTL4 expression and endothelial permeability. Furthermore, whether and how losartan, an angiotensin II (Ang II) type 1 receptor blocker (ARB), inhibited AGEs-induced ANGPTL4 expression was examined in endothelial cells.

\section{Materials and methods}

Materials. AGEs were from Merck KGaA (Darmstadt, Germany). Bovine serum albumin (BSA) (essentially fatty acid free and globulin free, lyophilized powder) was from MP Biomedicals (Santa Ana, CA, USA). Ang II kits were from RayBiotech, Inc. (Norcross, GA, USA). Losartan was from Sigma (St. Louis, MO, USA). The ANGPTL4 antibody was from Invitrogen Life Technologies (Carlsbad, CA, USA). TRIzol and SYBR Premix Ex Taq (Perfect Real Time) were from Takara Bio, Inc., (Shiga, Japan). Cell lysates were from Cell Signaling Technology, Inc. (Danvers, MA, USA) and fluorescein isothiocyanate (FITC, Inc.) dextran was from Sigma. The millicell-electrical resistance system (ERS) was from Millipore (Billerica, MA, USA). Transwell chambers (0.4 and $8 \mu \mathrm{M}$ ) were from Corning Inc. (Acton, MA, USA).

Cell culture. The EA.hy926 human endothelial cell line was from the American Type Culture Collection (Manassas, VA, 
USA). Cells were cultured in Dulbecco's modified Eagle's Medium (DMEM) with $5.5 \mathrm{mM}$ glucose containing essential and non-essential amino acids $(8.9 \mathrm{mg} / \mathrm{l} \mathrm{L}$-alanine, $13.3 \mathrm{mg} / \mathrm{l}$ aspartic acid, $15 \mathrm{mg} / \mathrm{l} \mathrm{L}$-asparagine, $14.7 \mathrm{mg} / 1$ monosodium glutamate and $11.5 \mathrm{mg} / \mathrm{l}$ proline $)$, sodium selenite $(0.02 \mathrm{mg} / \mathrm{l})$, ascorbic acid (10 mg/l), 10\% fetal bovine serum (FBS; v/v) and antibiotics (100 U/ml penicillin, $100 \mathrm{mg} / \mathrm{ml}$ streptomycin and $50 \mathrm{mg} / \mathrm{ml}$ neomycin), maintained at $37^{\circ} \mathrm{C}$ under $5 \% \mathrm{CO}_{2}$ in a humidified incubator. Confluent quiescent cells cultured for $24 \mathrm{~h}$ in serum-free DMEM with $5.5 \mathrm{mM}$ glucose were exposed for an additional $24 \mathrm{~h}$ to DMEM with the indicated concentrations of AGEs $(20-160 \mu \mathrm{g} / \mathrm{ml})$ in the absence or presence of ARB losartan $\left(10^{-5} \mathrm{M}\right)$.

Quantitative polymerase chain reaction ( $q P C R)$. Total RNA was extracted from endothelial cells using TRIzol reagent (Invitrogen Life Technologies) according to the manufacturer's instructions. Total RNA (500 ng) from different groups was reverse transcribed using reverse transcription in a SYBR Premix Ex Taq kits (Perfect Real Time). Reactions were carried out at $37^{\circ} \mathrm{C}$ for $15 \mathrm{~min}$, and subsequently $85^{\circ} \mathrm{C}$ for 5 sec. Primers were: ANGPTL4 sense, 5'-TCCTGGGACGAG ATGAATGT-3' and antisense,5'-GGTCTAGGTGCTTGTGGT C-3; and GAPDH sense, 5'-GAGTCCACTGGCGTCTTCA-3' and antisense, 5'-GGGGTGCTAAGCAGTTGGT-3'. PCR was performed with an ABI Prism 7000 Sequence Detection System (Applied Biosystems, Foster City, CA, USA) and the SYBR Premix Ex Taq Perfect Real Time kits.

Western blot analysis. Endothelial cells were washed twice with cold phosphate-buffered saline (PBS) and scraped with lysis buffer containing $20 \mathrm{mM}$ Tris- $\mathrm{HCl}(\mathrm{pH} 7.5), 150 \mathrm{mM}$ $\mathrm{NaCl}, 1 \mathrm{nM} \mathrm{Na}{ }_{2}$ EDTA, $1 \mathrm{mM}$ EGTA, $1 \%$ Triton X-100, $2.5 \mathrm{mM}$ sodium pyrophosphate, $1 \mathrm{mM} \beta$-glycerophosphate, $1 \mathrm{mM} \mathrm{Na} \mathrm{VO}_{4}, 1 \mu \mathrm{g} / \mathrm{ml}$ leupeptin (Cell Signaling Technology, Inc.) and protease and phosphatase inhibitor cocktail tablets (Roche Diagnostics GmbH, Mannhein, Germany). Protein concentrations were determined with the Bradford reaction. A total of $20 \mu \mathrm{g}$ boiled extracts was loaded on $8 \%$ sodium dodecyl sulphate-polyacrylamide gel electrophoresis gels and transferred to polyvinylidene fluoride membranes (Bio-Rad, Hercules, CA, USA). Membranes were blocked in 5\% skimmed milk prior to incubation with the antibody. Primary antibodies were: Rabbit anti-ANGPTL4 (1:2,000, Bio-Rad) and rabbit anti-GAPDH (1:2,000, Invitrogen Life Technologies). The blots were incubated with horseradish peroxidase-conjugated secondary antibodies (Santa Cruz Biotechnology, Inc., Dallas, TX, USA) and bands were detected using an ECL chemiluminescence system (Millipore).

Measurement of Ang II. Ang II levels were determined in cell lysates and media. Endothelial cells were harvested in $1 \%$ FBS medium for $24 \mathrm{~h}$ and cultured in control and experimental conditions. Cells were washed with ice-cold PBS, scraped in extraction buffer and homogenized. Lysates and media were centrifuged at $12,000 \mathrm{x}$ g for $10 \mathrm{~min}$ at $4^{\circ} \mathrm{C}$ and supernatants were collected. Ang II levels in lysates and media were determined using a commercial enzyme-linked immunosorbent assay (ELISA) kit according to the manufacturer's instructions.
Permeability assays. Paracellular permeability through the end monolayer was measured. Endothelial cells were cultured to confluency on gelatin-coated (1\%) polystyrene filters (Costar Transwell, 0.4- $\mu \mathrm{m}$ pore size) (Corning Inc.) for 3 days and $1 \mathrm{mg} / \mathrm{ml} 38 \mathrm{kDa}$ FITC-dextran (Sigma) was added in the apical compartment. Fluid in the lower compartment was the same serum-free medium without BSA. Transfer rates across the monolayer were assessed by measuring the increase in FITC-dextran in the lower well after $30 \mathrm{~min}$. At indicated times, $50 \mu \mathrm{l}$ samples were taken from the lower compartment to measure fluorescence $(492 / 520 \mathrm{~nm})$ using a multilabel fluorometer counter (Perkin-Elmer, Waltham, MA, USA) and normalized to the control value.

Transendothelial electrical resistance (TEER). Measurement of TEER was performed using a millicell-ERS (Millipore). Endothelial cells were grown to confluence in 8-well gold electrode plates in low serum media (DMEM low glucose; Gibco, Invitrogen Life Technologies, containing 1\% heat-inactivated FBS; Sigma). A current was applied across electrodes with an amplitude of $1 \mathrm{~V}$ in series with a resistance of $1 \mathrm{mV}$ to approximate a constant current source $(1 \mathrm{~mA})$. In-phase and out-of-phase voltages between electrodes were monitored and converted to TEER. Baseline resistance for each cell preparation was measured immediately before experimental manipulation.

Statistical analysis. Results are presented as mean \pm standard deviation. Statistical significance was assessed by non-parametric Kruskal-Wallis one-way analysis of variance or a Student's t-test. For statistical comparisons of clinical values prior and subsequent to losartan treatment, unpaired t-tests were performed. $\mathrm{P}<0.05$ was considered to indicate a statistically significant difference.

\section{Results}

AGEs upregulate ANGPTL4 $\mathrm{mRNA}$ and protein levels. AGEs at $0,20,40,80$ or $160 \mu \mathrm{g} / \mathrm{ml}$ were incubated with endothelial cells for $24 \mathrm{~h}$. ANGPTL $4 \mathrm{mRNA}$ and protein levels were assayed by qPCR and western blot analysis. AGEs at $80 \mu \mathrm{g} / \mathrm{ml}$ increased ANGPTL4 mRNA and protein levels significantly $(2.60 \pm 0.18$ vs. $1.00,250 \pm 32$ vs. $100 \%$, respectively; $\mathrm{P}<0.05)$. BSA had no effect on ANGPTL4 levels in endothelial cells (P>0.05) (Fig. 1).

AGEs increase Ang II levels in media and endothelial cell lysates. AGEs at $0,20,40,80$ or $160 \mu \mathrm{g} / \mathrm{ml}$ were incubated with endothelial cells for $24 \mathrm{~h}$. Ang II levels in media and lysates were measured by ELISA. AGEs dose-dependently increased Ang II levels in media and lysates. AGEs at $80 \mu \mathrm{g} / \mathrm{ml}$ had the largest effect. AGEs at $160 \mu \mathrm{g} / \mathrm{ml}$ did not have additional effects, although the effects remained significant $(\mathrm{P}<0.05)$. BSA had no effect on Ang II levels (P>0.05) (Table I).

Losartan alleviates the upregulation of ANGPTL4 and the increased endothelial permeability induced by AGEs. To investigate the effects of losartan on induction of ANGPTL4 expression, AGEs were used to upregulate the expression of ANGPTL4 mRNA and protein. Pretreatment with losartan prevented upregulation of ANGPTL4 mRNA and protein 
Table I. Advanced glycation end products (AGEs) increased angiotensin II levels in conditioned media and cell lysates.

\begin{tabular}{lcc}
\hline Groups & Media, pg/ $\mu 1$ & Lysates, $\mathrm{pg} / \mu \mathrm{g}$ protein \\
\hline Con & $1.3 \pm 0.19$ & $0.19 \pm 0.04$ \\
A20 & $1.6 \pm 0.22$ & $0.21 \pm 0.05$ \\
A40 & $2.1 \pm 0.23^{\mathrm{a}}$ & $0.24 \pm 0.03^{\mathrm{a}}$ \\
A80 & $2.8 \pm 0.21^{\mathrm{a}}$ & $0.35 \pm 0.04^{\mathrm{a}}$ \\
A160 & $2.5 \pm 0.20^{\mathrm{a}}$ & $0.28 \pm 0.04^{\mathrm{a}}$ \\
BSA & $1.4 \pm 0.19$ & $0.20 \pm 0.03$ \\
F-value & 5.83 & 5.12 \\
P-value & 0.008 & 0.01 \\
\hline
\end{tabular}

${ }^{\mathrm{a}} \mathrm{P}<0.05$ compared with the control group. Con, control; A20, $20 \mu \mathrm{g} / \mathrm{ml}$ AGEs; A40, $40 \mu \mathrm{g} / \mathrm{ml}$ AGEs; A80, $80 \mu \mathrm{g} / \mathrm{ml}$ AGEs; A160, $160 \mu \mathrm{g} / \mathrm{ml}$ AGEs; BSA, bovine serum albumin $(80 \mu \mathrm{g} / \mathrm{ml})$.

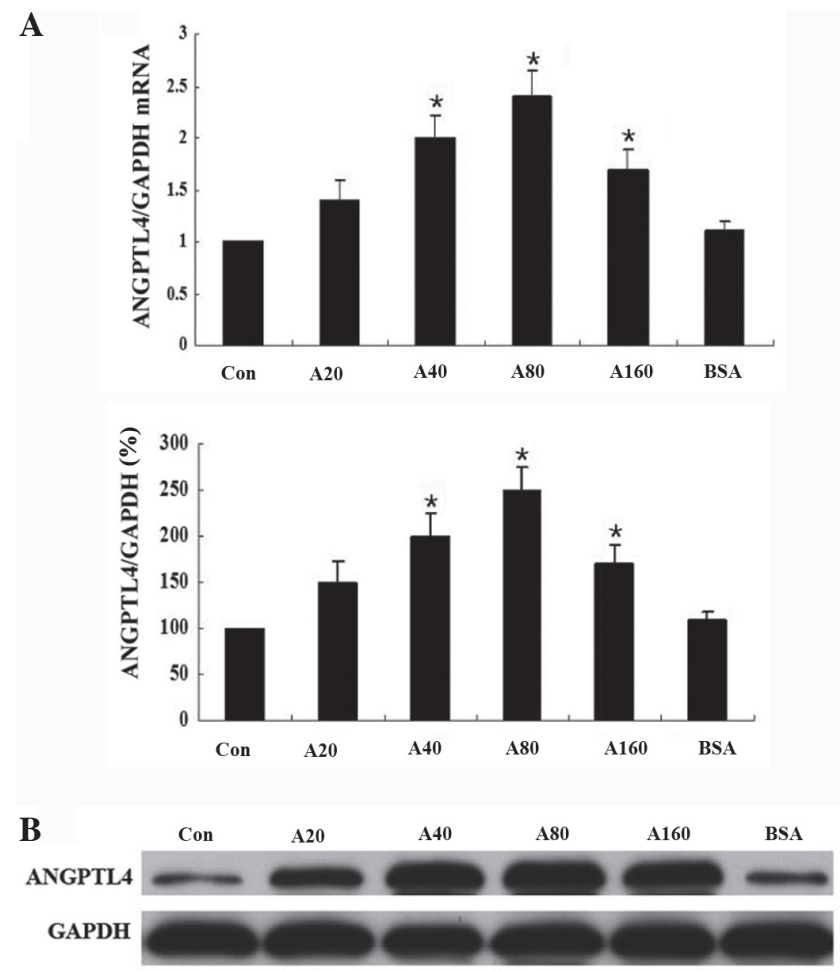

Figure 1. Advanced glycation end products (AGEs) upregulate angiopoietin-like protein 4 (ANGPTL4) (A) mRNA and protein. (B) Western blots. Con, control; A20, $20 \mu \mathrm{g} / \mathrm{ml}$ AGEs; A40, $40 \mu \mathrm{g} / \mathrm{ml}$ AGEs; A80, $80 \mu \mathrm{g} / \mathrm{ml}$ AGEs; A160, $160 \mu \mathrm{g} / \mathrm{ml}$ AGEs; BSA, bovine serum albumin $(80 \mu \mathrm{g} / \mathrm{ml})$. " $\mathrm{P}<0.05$ compared with the control group.

induced by AGEs ( $1.52 \pm 0.21$ vs. $2.60 \pm 0.18 ; 145 \pm 19$ vs. $250 \pm 32 \%$, respectively; $\mathrm{P}<0.05$ ) (Fig. 2). AGEs at $80 \mu \mathrm{g} / \mathrm{ml}$ increased endothelial permeability significantly and this increase was prevented by pretreatment with losartan $(\mathrm{P}<0.05)$ (Table II).

\section{Discussion}

Atherosclerosis is a common cardiovascular risk factor, and functional impairment of the vascular endothelium in response
Table II. Fluorescein isothiocyanate-labeled dextran filtration assays and transendothelial electrical resistance (TEER).

\begin{tabular}{lcc}
\hline Groups & OD & TEER, $\Omega \times \mathrm{cm}^{2}$ \\
\hline Con & $0.15 \pm 0.09$ & $73.28 \pm 2.64$ \\
A20 & $0.21 \pm 0.08$ & $68.24 \pm 3.12$ \\
A40 & $0.39 \pm 0.1^{\mathrm{a}}$ & $53.65 \pm 2.98^{\mathrm{a}}$ \\
A80 & $0.46 \pm 0.09^{\mathrm{a}}$ & $43.39 \pm 2.82^{\mathrm{a}}$ \\
A160 & $0.37 \pm 0.07^{\mathrm{a}}$ & $52.85 \pm 3.42^{\mathrm{a}}$ \\
BSA & $0.20 \pm 0.06$ & $70.77 \pm 2.83$ \\
AGEs + Los & $0.28 \pm 0.08^{\mathrm{a}, \mathrm{b}}$ & $62.43 \pm 3.18^{\mathrm{a}, \mathrm{b}}$ \\
F-value & 5.13 & 4.11 \\
P-value & 0.007 & 0.01 \\
\hline
\end{tabular}

${ }^{\mathrm{a}} \mathrm{P}<0.05$ compared with the control group; ${ }^{\mathrm{b}} \mathrm{P}<0.05$ compared with the A80 group. OD, optical density; con, control; A20, $20 \mu \mathrm{g} / \mathrm{ml}$ advanced glycation end products (AGEs); A40, $40 \mu \mathrm{g} / \mathrm{ml}$ AGEs; A80, $80 \mu \mathrm{g} / \mathrm{ml}$ AGEs; A160, $160 \mu \mathrm{g} / \mathrm{ml}$ AGEs; BSA, bovine serum albumin $(80 \mu \mathrm{g} / \mathrm{ml}) ;$ AGEs + Los, A80 + losartan $\left(10^{-5} \mathrm{M}\right)$.

$\mathbf{A}$
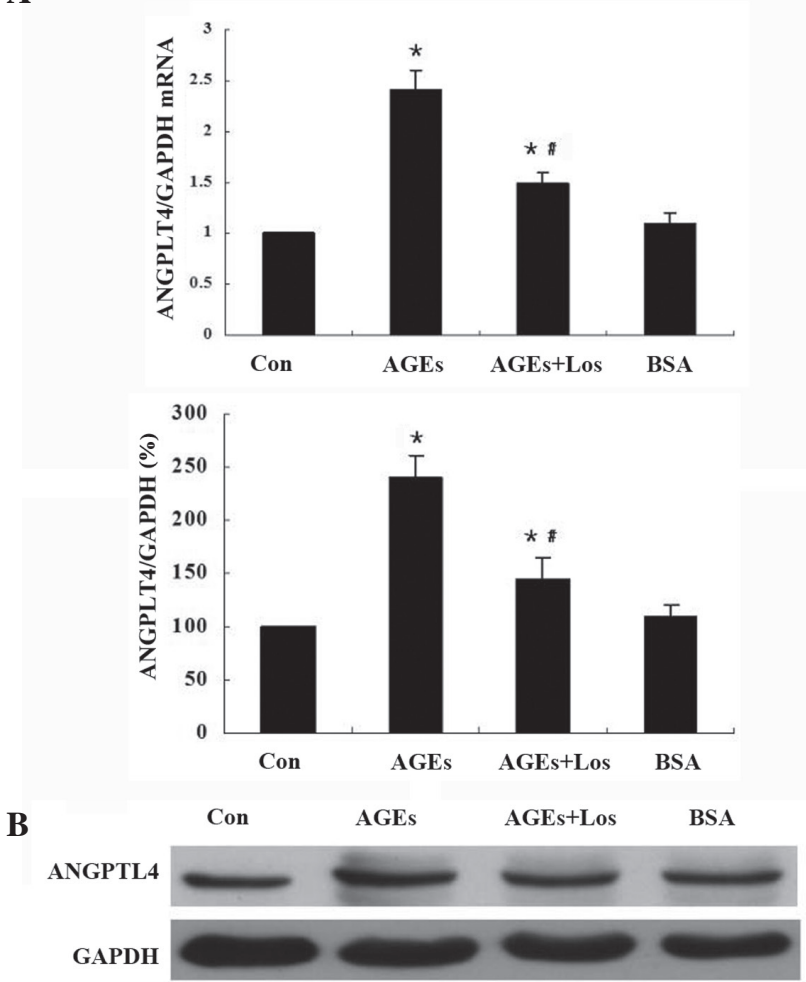

Figure 2. Losartan inhibits upregulation of angiopoietin-like protein 4 (ANGPTL4) (A) mRNA and protein induced by advanced glycation end products (AGEs). (B) Western blots. Con, control; A20, $20 \mu \mathrm{g} / \mathrm{ml}$ AGEs; A40, $40 \mu \mathrm{g} / \mathrm{ml}$ AGEs; A80, $80 \mu \mathrm{g} / \mathrm{ml}$ AGEs; A160, $160 \mu \mathrm{g} / \mathrm{ml}$ AGEs; BSA, bovine serum albumin $(80 \mu \mathrm{g} / \mathrm{ml})$; AGEs + Los, A80 + losartan $\left(10^{-5} \mathrm{M}\right) .{ }^{*} \mathrm{P}<0.05$ compared with the control group; ${ }^{*} \mathrm{P}<0.05$ compared with the $\mathrm{A} 80$ group.

to injury occurs long before the development of visible atherosclerosis (6). Diabetes increases CAD mortality in humans. Accelerated atherosclerosis and microvascular disease are the major vascular complications of diabetes and are the main cause of morbidity and mortality for this common metabolic 
disorder. However, established CAD risk factors do not fully account for increased CAD. Increasing attention has focused on the potential role of the endothelium in diabetes (6).

The most important pathway in the pathogenesis of accelerated atherosclerosis in patients with diabetes is most likely an increase in the non-enzymatic glycation of proteins and lipids, with the irreversible formation and deposition of reactive AGEs. Miyata et al (7) found that AGEs deposit in atherosclerotic plaques and interactions with endothelial cells release cytokines and growth factors, damaging endothelial cells. Due to its unique position and numerous properties, the vascular endothelium is particularly important in regulation of permeability. AGEs receptors have been found on the endothelial cell surface and mediate the uptake and transcytosis of AGEs and internal signal transduction. AGE-RAGE interactions alter barrier functions, as documented by increased permeability of endothelial cells incubated with AGEs and increased transit of macromolecules through the endothelial monolayer.

ANGPTL4 expression is upregulated in endothelial cells exposed to hypoxia and in ischemic tissues and hypoxic areas of solid tumors, which is important in angiogenesis, cell migration and adhesion (2). The present results showed that AGEs upregulated ANGPTL4 expression, particularly at $80 \mu \mathrm{g} / \mathrm{ml}$. However, the effects were not increased at $160 \mu \mathrm{g} / \mathrm{ml}$, but remained significant. ANGPTL4 is one of the vascular endothelial growth factor family. In addition to regulating lipid metabolism and insulin sensitivity, increasing evidence suggests that ANGPTL4 is an important modulator of angiogenesis and vascular permeability. Endothelial dysfunction is a principal mechanism in atherosclerotic disease. The effect of ANGPTL4 on endothelial permeability is controversial. Galaup et al (3) found that ANGPTL4 prevents tumor metastasis through inhibition of vascular permeability, tumor cell motility and invasiveness. However, more recent studies $(4,5)$ showed that ANGPTL4 in cancer cells disrupts vascular endothelial cell-cell junctions, increases the permeability of lung capillaries and facilitates the transendothelial passage of tumor cells. Upregulation of ANGPTL4 has a prominent effect on promoting the angiogenesis and vessel permeability in Kaposi's sarcoma (8). Inhibition of ANGPTL4 effectively blocks G protein-coupled receptor promotion of the angiogenic switch, vascular leakage in vitro and tumorigenesis in vivo (5). Our results showed that AGEs upregulated ANGPTL4 expression, increased endothelial permeability and decreased TEER $(\mathrm{P}<0.05)$. The ANGPTL4 effects in endothelial permeability are controversial due to the lack of understanding regarding how ANGPTL4 modulates vascular integrity. Huang et al (9) found that ANGPTL4 disrupts endothelial continuity by directly interacting with three novel binding partners sequentially: Integrin $\alpha 5 \beta 1$, VE-cadherin and claudin- 5 , activating integrin $\alpha 5 \beta 1$-mediated Rac1/PAK signaling to weaken cell-cell contacts, facilitating metastasis. Interfering with the formation of ANGPTL4 complexes delays vascular disruption. Cazes et al (10) found that extracellular matrix-bound ANGPTL4 increases endothelial permeability by alterations in the physical integrity of the endothelium, as shown by destruction of organized actin structures and alterations of cellular morphology. These results showed that ANGPTL4 damages endothelial cells and increases endothelial permeability via different mechanisms. ANGPTL4 may be essential for atherosclerosis by vascular permeability.
A previous study found that upregulation of ANGPTL4 is important in the development and progression of atherosclerosis, and knockout of ANGPTL4 prohibited the progress of atherosis (11). Cellular permeability has profound effects on atherosclerosis. However, the mechanism by which ANGPTL4 promotes atherosis is not known $(11,12)$. Adachi et al (11) found that ANGPTL4 deficiency improves lipid metabolism, suppresses foam cell formation and protects against atherosclerosis in genetic knockout mice. Xu et al (13) found that ANGPTL4 decreases blood glucose and improves glucose tolerance but induces hyperlipidemia and hepatic steatosis in mice. A previous study found that ANGPTL4 regulates fat metabolism and may have other effects on atherosclerosis (14). ANGPTL4 reduced tissue free fatty acid (FFA) uptake in skeletal muscle, heart and adipose tissue, resulting in hypertriglyceridemia by inhibiting lipoprotein lipase-mediated hydrolysis of plasma triglycerides to FFAs. Coronary atherosclerosis is initiated by endothelial dysfunction following inflammation and high levels of low-density lipoprotein cholesterol, followed by deposition of lipids and macrophages from the luminal blood into the arterial intima, resulting in plaque formation (15).

Ang II is crucial for promoting cardiovascular remodeling through induction of growth factors. Blockade of Ang II signaling appears to be a useful strategy for treating atherosclerosis. Ang II also stimulates growth and proliferation factors, activates inflammation and promotes expression of pro-inflammatory and pro-atherogenic cytokines. These effects prompt development and progress of atherosclerosis and complications. Yu et al (14) reported the local renin-angiotensin system (RAS) activation in endothelial cells and that local Ang II induces endothelial cell damage. The present results showed AGEs dose-dependently increased Ang II levels in conditioned media and cell lysates. However, whether local RAS in endothelial cells are involved in ANGPTL4 regulation remains unclear. The effects of losartan on ANGPTL4 expression and endothelial permeability were observed. Endothelial cells were pretreated with losartan prior to the addition of AGEs. The results showed that the increase in ANGPTL4 was prevented by losartan and the increased endothelial permeability improved. Villa et al (16) identified that telmisartan downregulated the expression of ANGPTL4 in podocytes, correlating with the amelioration of proteinuria and podocyte damage, largely independent of lowering blood pressure. Increased permeability of the endothelium is thought to be crucial in atherosclerosis as it allows circulating lipoproteins and inflammatory cells to infiltrate into the intima, which is a necessary step in atherosclerosis.

The permeability of endothelial cells is important for initiating and developing atherosclerosis. Atherosclerosis is a diffuse disease and endothelial dysfunction occurs at the initial stage of the atherosclerotic disease that generates plaque formation; it can also cause plaque growth without protection from high-risk plaques, leading to development of a vascular event. AGE-increased endothelial cell permeability is medicated by local activation of the RAS and upregulation of ANGPTL4, which provides a novel mechanism for AGE-induced endothelial dysfunction. ANGPTL4 is an important regulator in endothelial permeability. ANGPTL4, originally identified as a peroxisome proliferator-activated 
receptor $\alpha$ and $\gamma$ target gene, has potential as a new diagnostic tool and therapeutic target.

In conclusion, AGEs activated RAS in endothelial cells and upregulated ANGPTL4 mRNA and protein expression, which may be an alternative mechanism by which AGEs increase endothelial permeability. Further research of the regulatory mechanisms and signaling pathways could have profound significance. Evaluating whether Ang II receptor knockdown by small interfering RNA inhibited AGE-induced ANGPTL4 induction in endothelial cells may be noteworthy.

\section{Acknowledgements}

The study was supported by the National Natural Science Foundation of China (grant no. 81070581) and Science and Technology Planning Project of Guangdong, China (grant nos. 2010B031600202 and 2011B080701005).

\section{References}

1. Ladeia AM, Sampaio RR, Hita MC and Adan LF: Prognostic value of endothelial dysfunction in type 1 diabetes mellitus. World J Diabetes 5: 601-605, 2014.

2. Le Jan S, Amy C, Cazes A, Monnot C, Lamandé N, Favier J, Philippe J, Sibony M, Gasc JM, Corvol P, et al: Angiopoietin-like 4 is a proangiogenic factor produced during ischemia and in conventional renal cell carcinoma. Am J Pathol 162: 1521-1528, 2003.

3. Galaup A, Cazes A, Le Jan S, Philippe J, Connault E, Le Coz E, Mekid H, Mir LM, Opolon P, Corvol P, et al: Angiopoietin-like 4 prevents metastasis through inhibition of vascular permeability and tumor cell motility and invasiveness. Proc Natl Acad Sci USA 103: 18721-18726, 2006.

4. Padua D, Zhang XH, Wang Q, Nadal C, Gerald WL, Gomis RR and Massagué J: TGFbeta primes breast tumors for lung metastasis seeding through angiopoietin-like 4. Cell 133: 66-77, 2008

5. Ma T, Jham BC, Hu J, Friedman ER, Basile JR, Molinolo A, Sodhi A and Montaner S: Viral G protein-coupled receptor up-regulates Angiopoietin-like 4 promoting angiogenesis and vascular permeability in Kaposi's sarcoma. Proc Natl Acad Sci USA 107: 14363-14368, 2010.
6. Bae J, Kim IJ, Hong SH, Sung JH, Lim SW, Cha DH, Cho YW, Oh D and Kim NK: Association of endothelial nitric oxide synthase polymorphisms with coronary artery disease in Korean individuals with or without diabetes mellitus. Exp Ther Med 1: 719-724, 2010.

7. Miyata T, Kurokawa K and van Ypersele de Strihou C: Relevance of oxidative and carbonyl stress to long-term uremic complications. Kidney Int Suppl 76: S120-S125, 2000.

8. Hu J, Jham BC, Ma T, Friedman ER, Ferreira L, Wright JM, Accurso B, Allen CM, Basile JR and Montaner S: Angiopoietin-like 4: A novel molecular hallmark in oral Kaposi's sarcoma. Oral Oncol 47: 371-375, 2011.

9. Huang RL, Teo Z, Chong HC, Zhu P, Tan MJ, Tan CK, Lam CR, Sng MK, Leong DT, Tan SM, et al: ANGPTL4 modulates vascular junction integrity by integrin signaling and disruption of intercellular VE-cadherin and claudin-5 clusters. Blood 118: 3990-4002, 2011.

10. Cazes A, Galaup A, Chomel C, Bignon M, Bréchot N, Le Jan S, Weber H, Corvol P, Muller L, Germain S, et al: Extracellular matrix-bound angiopoietin-like 4 inhibits endothelial cell adhesion, migration, and sprouting and alters actin cytoskeleton. Circ Res 99: 1207-1215, 2006.

11. Adachi H, Fujiwara Y, Kondo T, Nishikawa T, Ogawa R, Matsumura T, Ishii N, Nagai R, Miyata K, Tabata M, et al: Angptl 4 deficiency improves lipid metabolism, suppresses foam cell formation and protects against atherosclerosis. Biochem Biophys Res Commun 379: 806-811, 2009.

12. Lichtenstein L and Kersten S: Modulation of plasma TG lipolysis by Angiopoietin-like proteins and GPIHBP1. Biochim Biophys Acta 1801: 415-420, 2010

13. Xu A, Lam MC, Chan KW, Wang Y, Zhang J, Hoo RL, Xu JY, Chen B, Chow WS, Tso AW, et al: Angiopoietin-like protein 4 decreases blood glucose and improves glucose tolerance but induces hyperlipidemia and hepatic steatosis in mice. Proc Natl Acad Sci USA 102: 6086-6091, 2005.

14. Yu MA, Sánchez-Lozada LG, Johnson RJ and Kang DH: Oxidative stress with an activation of the renin-angiotensin system in human vascular endothelial cells as a novel mechanism of uric acid-induced endothelial dysfunction. J Hypertens 28: 1234-1242, 2010.

15. Subbotin VM: Neovascularization of coronary tunica intima (DIT) is the cause of coronary atherosclerosis. Lipoproteins invade coronary intima via neovascularization from adventitial vasa vasorum, but not from the arterial lumen: A hypothesis. Theor Biol Med Model 9: 11, 2012.

16. Villa L, Boor P, Konieczny A, Kunter U, van Roeyen CR, Denecke B, Gan L, Kupper MB, Hoffmann K, Eitner F, et al: Effects and mechanisms of angiotensin II receptor blockade with telmisartan in a normotensive model of mesangioproliferative nephritis. Nephrol Dial Transplant 26: 3131-3143, 2011. 